\title{
Modelling trimmed fat from commercial primal cuts
}

\author{
Y.C.S.M. Laurenson, B.J. Walmsley, V.H. Oddy, P.L. Greenwood and $\underline{\text { M.J. McPhee }}$ \\ NSW Department of Primary Industries, Trevenna Rd, Armidale, NSW 2351 \\ Email: malcolm.mcphee@dpi.nsw.gov.au
}

\begin{abstract}
A number of studies over the last five years have been conducted to determine total body fat $(\mathrm{kg})$ in cattle and subsequently retail beef yield. Abattoirs are not consistent in the quantity of fat they trim off commercial bone-out primal cuts (e.g., striploin, cube roll etc.). The trimming of fat on a single primal by different abattoirs can range from 3 to $7 \mathrm{~mm}$. If a relationship between $\mathrm{mm}$ of fat trimmed and $\mathrm{kg}$ of fat removed from primal cuts was developed then total body fat $(\mathrm{kg})$ from commercial slaughters could then be estimated. The estimate of total body fat would assist in establishing a method for determining denuded yield which would then be used as a national standard for describing retail beef yield independent of abattoir. The estimate of retail beef yield would then be implemented into the BeefSpecs calculator.

The objective of this study was to develop a relationship between trim ( $\mathrm{mm}$ ) and $\mathrm{kg}$ of fat removed. Images from X-ray computed tomography (CT) scans of 8 primal cuts from 10 Angus steers were manipulated to generate CT scan images for trims ranging from 0 to $15 \mathrm{~mm}$. These images were analysed to determine the weights of fat and muscle in each primal, which were subsequently converted to ratios. Eleven non-linear growth functions were fitted to the generated data and compared to assess their ability to accurately predict the trimmed muscle ratio. The Schnute growth function was identified as the best fit model with the lowest $A I C c$ (corrected Akaike's Information Criterion) $\left(A I C c=-480.879\right.$, adjusted $\left.R^{2}=0.945, R M S E=0.023\right)$. The proposed model (and parameter estimates) can be used to estimate the $\mathrm{kg}$ of fat removed and therefore aid in the estimation of retail beef yield.
\end{abstract}

Keywords: CT scanning, images, retail beef yield, growth functions 


\section{INTRODUCTION}

A number of studies (unpublished) over the last five years have been conducted to determine total body fat $(\mathrm{kg})$ in cattle and subsequently retail beef yield. Abattoirs are not consistent in the quantity of fat they trim off commercial bone-out primal cuts (e.g., Striploin, Cube Roll etc.). The trimming of fat on a single primal by different abattoirs can range from 3 to $7 \mathrm{~mm}$. If a relationship between $\mathrm{mm}$ of fat trimmed and $\mathrm{kg}$ of fat removed was developed then total body fat $(\mathrm{kg})$ from commercial slaughters could be estimated. The estimate of total body fat would assist in establishing a method for determining denuded yield to be used as a national standard for describing retail beef yield independent of abattoir. The estimate of retail beef yield would then be implemented into the BeefSpecs calculator (Walmsley et al., 2011). Thus, the purpose of this study is to develop a model that will convert mm of fat trimmed off primal cuts to $\mathrm{kg}$ of fat removed.

\section{MATERIAL AND METHODS}

\subsection{Animal management \& slaughter}

This study was carried out using 10 weaned Angus steers. From weaning, five steers were fed pasture and five steers were fed pasture plus high energy pellets (12.3 MJ ME/kg DM, $110 \mathrm{~g} \mathrm{CP} / \mathrm{kg} \mathrm{DM})$ at $1 \%$ live weight for 168 days. All steers were then backgrounded (management of post-weaning growth to produce feeder steer that meet feedlot entry specifications) until 18 months of age when they were feedlot fed for 250 days until slaughter in August 2010. Live weight did not differ due to nutritional treatment at any stage (Greenwood et al., 2011). The average ( \pm s.e.) age, live weight and empty body weight at slaughter were 788 $( \pm 4.6)$ days, $805( \pm 23.6) \mathrm{kg}$ and $688( \pm 20.2) \mathrm{kg}$, respectively. After slaughter, the left carcass sides were cut into 20 primal cuts. Primal cuts were vacuum packed and transported (at $1-2^{\circ} \mathrm{C}$ ) to the University of New England Meat Sciences CT unit where they were weighed and X-ray computed tomography (CT) scanned.

\subsection{CT scanning}

Primal cuts were scanned using a Picker Ultra Z Spiral CT scanner (Philips Medical Imaging Australia, Sydney NSW). The X-ray tube operated at $130 \mathrm{kV}$ and $100 \mathrm{mAs}$. A pitch of 1.5, field of view of $480 \mathrm{~mm}$ and cross-sectional thickness of $15 \mathrm{~mm}$ were used. The chuck primal exceeded the field of view and was consequently separated into sub-primal cuts (chuck inter and chuck sub). Further, the flank and chuck sub exceeded the maximum length of the scanner table and consequently two contiguous scans were performed.

\subsection{Image analysis}

CT scans from 8 primal cuts (Striploin, Rump, Eye Round, Cube Roll, Chuck Tender, Blade, Chuck and Brisket) were analysed using Image $J$ software (National Institutes of Health, USA). The pixel to mm scale was set for each animal using the subcutaneous fat at the P8 (rump) site (measured by ultrasound) and the corresponding image. This led to a constant scale being used ( 2 pixels $=1 \mathrm{~mm})$.

\subsection{Tissue composition}

To infer the tissue composition of these primal cuts, histograms of the grey scale cross-sectional images were created and the resultant bimodal distribution was used to determine threshold values for fat and muscle. However, each cross-section does not contain an equal amount of information from which to estimate threshold values, and thus threshold values were weighted according to cross-section area to increase accuracy. The average ( \pm s.e.) upper threshold for fat (threshold 1) and muscle (threshold 2) was $120( \pm 0.5)$ and $214( \pm 0.8)$, respectively. As such, tissue was identified as fat if the grey scale units fell within the range between 0 and threshold 1, or as muscle for the range between threshold 1 and threshold 2 .

\subsection{Tissue and total primal weight}

Tissue weight for each section was calculated as (Navajas et al., 2010):

Tissue weight $(\mathrm{mg})=$ Tissue area $\left(\mathrm{mm}^{2}\right) *$ cross-sectional thickness $(\mathrm{mm}) *$ tissue density $\left(\mathrm{mg} / \mathrm{mm}^{3}\right)$

where, tissue (fat and muscle) areas were determined according to the thresholds derived above (section 2.4), cross-sectional thickness $(15 \mathrm{~mm})$, and assuming fixed values for tissue density (Fat $=0.918 \mathrm{mg} / \mathrm{mm}^{3}$, Muscle $\left.=1.062 \mathrm{mg} / \mathrm{mm}^{3}\right)$ (Nord \& Payne, 1995; Frigerio et al., 1972).

Total tissue weights for each primal were then calculated as the sum of the corresponding tissue weights for each cross-section, and the total primal weight was calculated as the sum of the total tissue (fat and muscle) weights for each primal. 


\subsection{Image manipulation}

Figure 1 provides an overview of the process used to generate cross-section images with specific depths of fat (trim, mm). In short, each cross-section was analysed to determine its tissue composition (section 2.4), and separate cross-section images created for fat and lean muscle. However, it is improbable that lean muscle can be completely separated from fat within the abattoir. Consequently the $0 \mathrm{~mm}$ trim cross-section image was generated using templates of the muscle translated by + or $-1 \mathrm{~mm}$ on the $\mathrm{x}$-axis and $-1 \mathrm{~mm}$ on the $\mathrm{y}$ axis. These templates were then superimposed upon each other and the resultant template subtracted from the initial cross-section image to generate an image of the trimmed fat for a $0 \mathrm{~mm}$ trim. A cross-section image for the trimmed muscle was then created by subtracting the $0 \mathrm{~mm}$ fat image from the initial greyscale crosssection image. Images of trimmed fat and muscle for increasing trim were generated using the same procedure with the addition of including templates shifted at $+1 \mathrm{~mm}$ intervals on the y-axis. Trimmed fat and muscle cross-section images were thereby generated for trims ranging from 0 to $15 \mathrm{~mm}$ at $1 \mathrm{~mm}$ intervals.

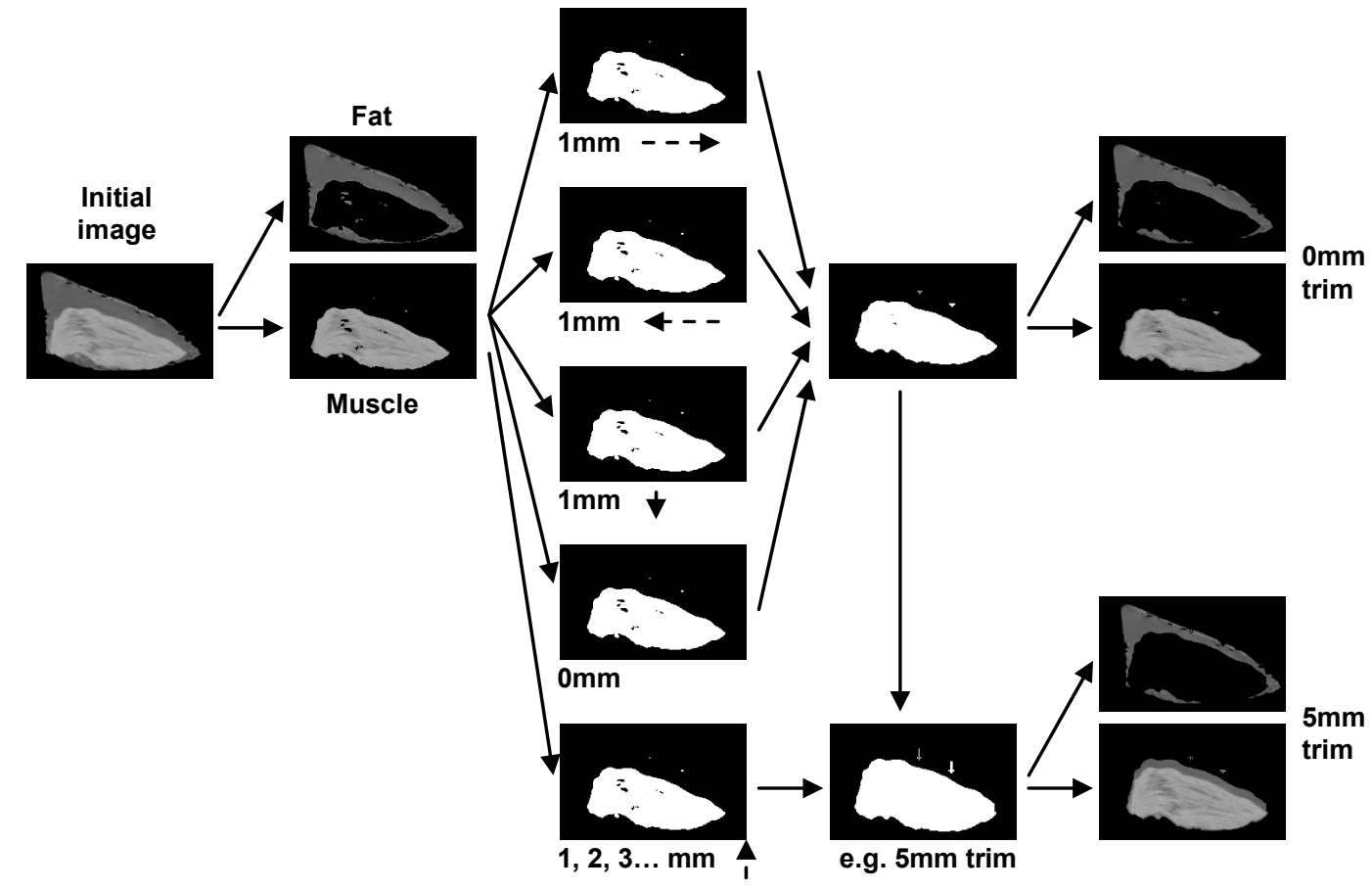

Figure 1. Overview of the procedure carried out within Image $\mathrm{J}$ to generate images of trimmed fat and muscle for trims ranging from 0 to $15 \mathrm{~mm}$ fat depth. Solid arrows indicate progression of procedure; dashed arrows indicate direction of image translation. Example provided is for section 8 of the Rump for animal 1.

\subsection{Trimmed fat and muscle weight/ratio}

The cross-section images of trimmed fat from trims ranging from $0 \mathrm{~mm}$ to $15 \mathrm{~mm}$ were analysed as described above (section 2.5) to obtain their weight (mg).

The cross-section weight (mg) of trimmed muscle was consequently calculated as:

Trimmed muscle $(\mathrm{mg})=$ total cross-section $(\mathrm{mg})$ - trimmed fat $(\mathrm{mg})$

Primal weights for trimmed fat and muscle are then calculated as the sum of each primal's cross-section images. Ratios for trimmed fat/total primal, and trimmed muscle/total primal were calculated from the estimated weights for each primal and each animal.

\subsection{Modelling the trimmed fat and muscle ratios}

Data generated (Equations 1 and 2; sections 2.6 and 2.7) was used to estimate parameters for 11 non-linear growth functions (Table 1). These parameter estimates define the y-intercept, upper asymptote and growth rate. However, the lean muscle ratio varies across primals and animals, leading to variation in parameter estimates (i.e. parameter estimates are not constant). Thus, parameters were described as their linear regression with lean muscle ratio, effectively doubling the number of parameters requiring estimation (gradient and y-intercept of linear regression for each of the parameters given in Table 1). Mircosoft ${ }^{\circledR}$-Excel 
Solver was used to estimate the parameter values which resulted in the algebraically lowest corrected Akaike's Information Criterion $(A I C c)$.

Akaike's information criterion (AIC) was calculated as (Akaike, 1974):

$A I C=n * \ln \left(R_{e}\right)+2 p$

where, $n$ is the sample size $[\mathrm{n}=1280$ (animals $*$ primals $*$ trims)], $p$ is the number of parameters $[4$ to 8 (doubling of parameters given in Table 1 due to linear regression with lean muscle ratio)] and $R_{e}$ is the residual sum of squares defined by:

$$
R_{e}=\sum_{i=1}^{n}\left(m_{i}-o_{i}\right)^{2}
$$

where, $o_{i}$ is the observed trimmed muscle ratio, $m_{i}$ is the modelled trimmed muscle ratio for the $i^{\text {th }}$ observation.

$A I C c$ is consequently calculated as (Hurvich \& Tsai, 1989):

$$
A I C c=A I C+\frac{2 p(p+1)}{n-p-1}
$$

The differing growth functions were subsequently compared by assessing their AICc values, adjusted $R^{2}$ and root mean square error (RMSE) to determine the most appropriate growth function to describe the relationship between trimmed muscle ratio and trim $(\mathrm{mm})$.

Adjusted $R^{2}$ was calculated as:

$$
\text { AdjustedR }^{2}=1-\frac{\left(1-R^{2}\right)(n-1)}{n-p-1}
$$

Table 1. Non-linear growth functions $(a, b, c$ and $d$ are parameters to be estimated; $x=\operatorname{trim}(\mathrm{mm}) ; \mathrm{p}=$ number of parameters). Adapted from Fekedulegn et al. (1999) \& Khamis et al. (2005).

\begin{tabular}{lll}
\hline \hline Model & Equation & p \\
Negative & $f(x)=a(1-\exp (-b x))$ & 2 \\
Monomolecular & $f(x)=a(1-b \exp (-c x))$ & 3 \\
Mitscherlich & $f(x)=a-b c^{x}$ & 3 \\
Gompertz & $f(x)=a \exp (-b \exp (-c x))$ & 3 \\
Logistic & $f(x)=a /(1+b \exp (-c x))$ & 3 \\
Schnute & $f(x)=(a+b \exp (c x))^{d}$ & 4 \\
Weibull & $f(x)=a-b \exp \left(-c x^{d}\right)$ & 4 \\
Richards & $f(x)=a /(1=b \exp (-c x))^{1 / d}$ & 4 \\
Chapman- & $f(x)=a(1-b \exp (-c x))^{1 /(1-d)}$ & 4 \\
Richards & $f(x)=\left(a^{1-d}-b \exp (-c x)\right)^{1 /(1-d)}$ & 4 \\
von Bertalanffy & $f(x)=\left(b c+a x^{d}\right) /\left(c+x^{d}\right)$ & 4 \\
Morgan- & $f(x)$ & \\
Mercer-Flodin & &
\end{tabular}

where, $R^{2}$ is the coefficient of determination

\begin{tabular}{|c|c|c|c|c|c|c|c|c|c|c|c|}
\hline \multirow[t]{2}{*}{ Beef Primal Cuts } & \multicolumn{11}{|c|}{ Animal } \\
\hline & 1 & 2 & 3 & 4 & 5 & 6 & 7 & 8 & 9 & 10 & Average ( \pm s.e.) \\
\hline \multicolumn{12}{|l|}{ Measured } \\
\hline \multicolumn{12}{|l|}{ Hind quarter } \\
\hline Striploin & 11.88 & 10.39 & 9.00 & 8.72 & 11.01 & 10.07 & 11.72 & 10.00 & 9.96 & 11.44 & $10.42(0.34)$ \\
\hline Rump & 12.26 & 11.02 & 10.66 & 11.66 & 11.52 & 12.80 & 13.48 & 12.19 & 11.55 & 11.67 & $11.88(0.26)$ \\
\hline Eye Round & 3.14 & 3.12 & 2.56 & 2.95 & 3.45 & 3.51 & 3.77 & 3.76 & 2.93 & 3.23 & $3.24(0.12)$ \\
\hline \multicolumn{12}{|l|}{ Fore quarter } \\
\hline Cube Roll & 3.63 & 3.64 & 2.98 & 3.95 & 4.53 & 3.62 & 4.10 & 4.41 & 3.60 & 3.97 & $3.84(0.14)$ \\
\hline Chuck Tender & 1.81 & 1.66 & 1.74 & 1.93 & 2.29 & 2.09 & 2.43 & 1.64 & 1.93 & 2.62 & $2.01(0.11)$ \\
\hline Blade & 10.65 & 8.47 & 8.90 & 11.13 & 11.23 & 12.46 & 12.48 & 10.97 & 8.58 & 10.74 & $10.56(0.46)$ \\
\hline Chuck & 33.34 & 28.46 & 27.07 & 30.91 & 35.04 & 32.86 & 36.30 & 33.18 & 29.36 & 41.11 & $32.76(1.31)$ \\
\hline Brisket & 31.19 & 24.06 & 21.50 & 22.60 & 26.46 & 24.35 & 26.57 & 27.37 & 22.05 & 24.15 & $25.03(0.93)$ \\
\hline \multicolumn{12}{|c|}{ CT scan estimation } \\
\hline \multicolumn{12}{|l|}{ Hind quarter } \\
\hline Striploin & 11.87 & 10.41 & 9.07 & 8.73 & 11.05 & 10.02 & 11.73 & 9.98 & 9.96 & 11.44 & $10.42(0.34)$ \\
\hline Rump & 12.26 & 11.04 & 10.69 & 11.70 & 11.51 & 12.90 & 13.65 & 12.29 & 11.53 & 11.73 & $11.93(0.28)$ \\
\hline Eye Round & 3.12 & 3.13 & 2.54 & 2.94 & 3.41 & 3.46 & 3.72 & 3.75 & 2.90 & 3.20 & $3.22(0.12)$ \\
\hline \multicolumn{12}{|l|}{ Fore quarter } \\
\hline Cube Roll & 3.61 & 3.71 & 2.99 & 4.03 & 4.56 & 3.66 & 4.15 & 4.43 & 3.63 & 3.98 & $3.87(0.14)$ \\
\hline Chuck Tender & 1.77 & 1.64 & 1.75 & 1.93 & 2.29 & 2.12 & 2.44 & 1.62 & 1.92 & 2.60 & $2.01(0.11)$ \\
\hline Blade & 10.65 & 8.50 & 8.97 & 11.19 & 11.31 & 12.56 & 12.50 & 11.02 & 8.60 & 10.75 & $10.60(0.47)$ \\
\hline Chuck & 33.66 & 28.79 & 27.44 & 31.24 & 35.46 & 33.28 & 36.80 & 33.27 & 29.65 & 41.51 & $33.11(1.32)$ \\
\hline Brisket & 31.18 & 24.24 & 21.72 & 17.04 & 26.60 & 24.69 & 26.86 & 27.50 & 22.11 & 24.39 & $24.63(1.21)$ \\
\hline
\end{tabular}

Table 2. Measured and CT scan estimation of primal weights $(\mathrm{kg})$. Primal weights are provided for each animal as well as their mean average ( \pm s.e.). 
$R M S E$ was calculated as:

$$
R M S E=\sqrt{\frac{R_{e}}{n}}
$$

\section{RESULTS}

\subsection{Validating CT scan estimated weights}

Table 2 provides the measured and CT scan estimated weights for each primal, given as individual animal primal weights and as a mean average ( \pm s.e). The estimation of primal weights using CT scanning was very accurate when making a comparison with the measured (observed) weights $\left(R^{2}=0.996\right)$.

\subsection{Trimmed muscle ratio}

Figure 2 gives the mean lean muscle ratio and mean trimmed muscle ratio (for 0 to $15 \mathrm{~mm}$ trim) for the Rump primal (given as an example of the relationship between trim and trimmed muscle ratio). Results from other primal cuts followed a similar profile differing only in the lean muscle ratio and the rate at which the trimmed muscle ratio approaches the upper asymptote. Table 3 provides the mean $( \pm$ s.e.) trimmed muscle ratio for each of the 8 primal cuts and for lean, $0 \mathrm{~mm}, 1 \mathrm{~mm}, 2 \mathrm{~mm}, \ldots, 14 \mathrm{~mm}$ and $15 \mathrm{~mm}$ trims.

Table 3. Average ( \pm s.e.) ratio of trimmed muscle weight to total primal weight for each of the 8 primal cuts. Values (rounded to 3 decimal places) are provided for lean, $0 \mathrm{~mm}, 1 \mathrm{~mm}, 2 \mathrm{~mm}, \ldots, 14 \mathrm{~mm}$ and $15 \mathrm{~mm}$ trims.

\begin{tabular}{|c|c|c|c|c|c|c|c|c|}
\hline \multirow{3}{*}{$\begin{array}{l}\text { Trim } \\
(\mathrm{mm})\end{array}$} & \multicolumn{8}{|c|}{ Beef Primal Cuts } \\
\hline & \multicolumn{3}{|c|}{ Hind quarter } & \multicolumn{5}{|c|}{ Fore quarter } \\
\hline & Striploin & Rump & $\begin{array}{c}\text { Eye } \\
\text { Round }\end{array}$ & Cube Roll & $\begin{array}{l}\text { Chuck } \\
\text { Tender }\end{array}$ & Blade & Chuck & Brisket \\
\hline \multirow[t]{2}{*}{ lean } & 0.657 & 0.604 & 0.749 & 0.752 & 0.825 & 0.734 & 0.654 & 0.485 \\
\hline & $(0.015)$ & $(0.010)$ & $(0.006)$ & $(0.009)$ & $(0.016)$ & $(0.007)$ & $(0.009)$ & $(0.010)$ \\
\hline \multirow[t]{2}{*}{0} & 0.698 & 0.652 & 0.795 & 0.835 & 0.877 & 0.786 & 0.718 & 0.552 \\
\hline & $(0.015)$ & $(0.010)$ & $(0.007)$ & $(0.008)$ & $(0.015)$ & $(0.006)$ & $(0.009)$ & $(0.011)$ \\
\hline \multirow[t]{2}{*}{1} & 0.710 & 0.662 & 0.807 & 0.852 & 0.889 & 0.798 & 0.734 & 0.575 \\
\hline & $(0.015)$ & $(0.010)$ & $(0.006)$ & $(0.007)$ & $(0.014)$ & $(0.007)$ & $(0.008)$ & $(0.011)$ \\
\hline \multirow[t]{2}{*}{2} & 0.728 & 0.678 & 0.824 & 0.874 & 0.904 & 0.815 & 0.753 & 0.601 \\
\hline & $(0.015)$ & $(0.010)$ & $(0.006)$ & $(0.006)$ & $(0.013)$ & $(0.007)$ & $(0.008)$ & $(0.011)$ \\
\hline \multirow[t]{2}{*}{3} & 0.746 & 0.694 & 0.840 & 0.893 & 0.917 & 0.829 & 0.770 & 0.625 \\
\hline & $(0.015)$ & $(0.010)$ & $(0.007)$ & $(0.006)$ & $(0.012)$ & $(0.007)$ & $(0.007)$ & $(0.011)$ \\
\hline \multirow[t]{2}{*}{4} & 0.764 & 0.709 & 0.854 & 0.909 & 0.928 & 0.842 & 0.785 & 0.647 \\
\hline & $(0.015)$ & $(0.011)$ & $(0.007)$ & $(0.005)$ & $(0.010)$ & $(0.007)$ & $(0.007)$ & $(0.012)$ \\
\hline \multirow[t]{2}{*}{5} & 0.781 & 0.724 & 0.868 & 0.923 & 0.938 & 0.853 & 0.793 & 0.666 \\
\hline & $(0.015)$ & $(0.011)$ & $(0.008)$ & $(0.004)$ & $(0.009)$ & $(0.007)$ & $(0.007)$ & $(0.012)$ \\
\hline \multirow[t]{2}{*}{6} & 0.798 & 0.738 & 0.879 & 0.934 & 0.947 & 0.863 & 0.809 & 0.685 \\
\hline & $(0.015)$ & $(0.011)$ & $(0.008)$ & $(0.004)$ & $(0.008)$ & $(0.007)$ & $(0.006)$ & $(0.011)$ \\
\hline \multirow[t]{2}{*}{7} & 0.814 & 0.751 & 0.889 & 0.944 & 0.953 & 0.871 & 0.819 & 0.701 \\
\hline & $(0.015)$ & $(0.011)$ & $(0.009)$ & $(0.003)$ & (0.007) & (0.007) & $(0.006)$ & $(0.011)$ \\
\hline \multirow[t]{2}{*}{8} & 0.830 & 0.764 & 0.895 & 0.951 & 0.958 & 0.879 & 0.828 & 0.716 \\
\hline & $(0.015)$ & $(0.011)$ & $(0.009)$ & $(0.003)$ & (0.007) & $(0.006)$ & $(0.006)$ & $(0.011)$ \\
\hline \multirow[t]{2}{*}{9} & 0.845 & 0.777 & 0.899 & 0.956 & 0.961 & 0.886 & 0.836 & 0.730 \\
\hline & $(0.014)$ & $(0.011)$ & $(0.010)$ & $(0.003)$ & (0.007) & $(0.006)$ & $(0.005)$ & $(0.011)$ \\
\hline \multirow[t]{2}{*}{10} & 0.859 & 0.788 & 0.902 & 0.960 & 0.963 & 0.892 & 0.843 & 0.743 \\
\hline & $(0.014)$ & $(0.011)$ & $(0.009)$ & $(0.003)$ & (0.007) & $(0.006)$ & $(0.005)$ & $(0.011)$ \\
\hline 11 & 0.871 & 0.799 & 0.904 & 0.963 & 0.963 & 0.898 & 0.850 & 0.754 \\
\hline \multirow{3}{*}{12} & $(0.013)$ & $(0.011)$ & $(0.009)$ & $(0.002)$ & $(0.006)$ & $(0.006)$ & $(0.005)$ & $(0.011)$ \\
\hline & 0.882 & 0.808 & 0.906 & 0.965 & 0.964 & 0.903 & 0.855 & 0.764 \\
\hline & $(0.013)$ & $(0.011)$ & $(0.009)$ & $(0.002)$ & $(0.006)$ & $(0.006)$ & $(0.005)$ & $(0.011)$ \\
\hline \multirow[t]{2}{*}{13} & 0.892 & 0.817 & 0.907 & 0.967 & 0.964 & 0.907 & 0.861 & 0.774 \\
\hline & $(0.012)$ & $(0.011)$ & $(0.009)$ & $(0.002)$ & (0.006) & $(0.006)$ & $(0.005)$ & $(0.011)$ \\
\hline \multirow[t]{2}{*}{14} & 0.900 & 0.825 & 0.909 & 0.969 & 0.965 & 0.911 & 0.866 & 0.782 \\
\hline & $(0.011)$ & $(0.011)$ & $(0.009)$ & $(0.002)$ & $(0.006)$ & $(0.006)$ & $(0.005)$ & $(0.010)$ \\
\hline \multirow[t]{2}{*}{15} & 0.908 & 0.832 & 0.910 & 0.971 & 0.965 & 0.915 & 0.870 & 0.790 \\
\hline & $(0.011)$ & $(0.011)$ & $(0.009)$ & $(0.002)$ & $(0.006)$ & $(0.006)$ & $(0.004)$ & $(0.010)$ \\
\hline
\end{tabular}




\subsection{Parameter estimation and model fit}

Table 4 provides the calculated parameter estimations for the growth functions described in Table 1.

Table 4. Parameter estimates (rounded to 3 decimal places) for differing growth functions. $a, b, c$ and $d$ are parameters to be estimated for the growth functions outlined in Table 1.r, s, t,u,v,w,y and $z$ are parameters to be estimated for the linear regression between parameters $a, b, c$ and $d$, and the lean muscle ratio $(q)$ for individual primal cuts.

\begin{tabular}{|c|c|c|c|c|c|c|c|c|c|}
\hline \multirow[t]{3}{*}{ Growth Model } & \multicolumn{8}{|c|}{ Parameter } & \multirow{3}{*}{$\begin{array}{c}\text { No. of } \\
\text { estimated } \\
\text { parameters }\end{array}$} \\
\hline & \multicolumn{2}{|c|}{$\boldsymbol{a}=r q+s$} & \multicolumn{2}{|c|}{$\boldsymbol{b}=t q+u$} & \multicolumn{2}{|c|}{$c=v q+w$} & \multicolumn{2}{|c|}{$\boldsymbol{d}=y q+z$} & \\
\hline & $r$ & $s$ & $t$ & $\boldsymbol{u}$ & $v$ & $w$ & $y$ & $z$ & \\
\hline $\begin{array}{c}\text { Negative } \\
\text { exponential }\end{array}$ & 0.726 & 0.356 & 3.708 & -0.562 & & & & & 4 \\
\hline Monomolecular & 0.026 & 0.012 & -11.01 & -16.64 & 0.051 & -0.048 & & & 6 \\
\hline Mitscherlich & 0.424 & 0.655 & -0.614 & 0.626 & -0.043 & 0.933 & & & 6 \\
\hline Gompertz & 0.014 & 0.005 & -0.358 & -3.670 & 0.012 & -0.012 & & & 6 \\
\hline Logistic & 0.416 & 0.639 & -1.190 & 1.086 & 0.163 & 0.039 & & & 6 \\
\hline Schnute & -7.550 & 7.810 & -79.39 & 74.08 & -0.021 & -0.253 & 0.342 & -0.331 & 8 \\
\hline Weibull & 0.496 & 0.577 & -0.531 & 0.537 & 0.029 & 0.066 & 0.191 & 1.069 & 8 \\
\hline Richard's & 0.407 & 0.654 & -0.530 & 0.501 & 0.090 & 0.069 & 0.254 & 0.366 & 8 \\
\hline Chapman-Richards & -0.063 & 0.065 & -0.600 & -1.517 & 0.028 & -0.025 & 0.309 & 0.483 & 8 \\
\hline Von Bertalanffy & 0.488 & 0.587 & -0.060 & 0.056 & 0.071 & 0.069 & 0.022 & 0.938 & 8 \\
\hline $\begin{array}{l}\text { Morgan-Mercer- } \\
\text { Flodin }\end{array}$ & -6971 & -2603 & 1.103 & -0.016 & 6311 & 3247 & 0.459 & 0.385 & 8 \\
\hline
\end{tabular}

Table 5 gives the AICc, adjusted $R^{2}$ and $R M S E$ for each of the growth functions investigated.

\section{DISCUSSION}

The Schnute growth function (Table 5) was identified as the best fit model (i.e. lowest $A I C c$ value $=-480.879$, highest adjusted $R^{2}=0.945$, and lowest $R M S E=0.023)$. For all growth functions the $A I C c$, adjusted $R^{2}$ and $R M S E$ altered in relation to each other, where reductions in adjusted $R^{2}$ was evident as an increase in $A I C c$ and RMSE. However, there was one notable exception. The Richards function had the second lowest $A I C C$ value of -437.315 and RMSE of 0.023 whilst the adjusted $R^{2}$ was 0.848 . The Richards growth function provided a very good fit for the majority of the data. However, it was not flexible enough to accurately estimate trimmed muscle ratio for higher trim values, resulting in several outliers.

These outliers had a large impact on the coefficient of determination, but not on calculations based on the residual sum of squares (i.e. residuals for outliers were diluted by the large number of very low residual values). These results highlight the importance of using more than one method to compare models. Further, the comparison between the $A I C c$ values for the negative exponential and the monomolecular growth functions (4931.95 and -150.368, respectively) highlights the necessity of including a parameter to determine the y-intercept. A mechanistic model, currently under development, will use the Schnute growth function to model trimmed fat to calculate total body fat and subsequently estimate retail beef yield which will be implemented into the BeefSpecs calculator (Walmsley et al., 2011).

\section{CONCLUSION}

The Schnute growth function (Schnute, 1981) was identified as the best fit model for estimating the relationship between trimmed muscle ratio and trim. Thus, the final model for estimating the trimmed muscle ratio is given as: growth models fitted to trimmed muscle ratio data.

\begin{tabular}{lccc}
\hline \hline Model & $\boldsymbol{A I C \boldsymbol { c }}$ & Adjusted $\boldsymbol{R}^{2}$ & $\boldsymbol{R M S E}$ \\
\hline Negative exponential & 4931.950 & 0.295 & 0.191 \\
Monomolecular & -150.368 & 0.929 & 0.026 \\
Mitscherlich & -418.712 & 0.942 & 0.024 \\
Gompertz & -135.063 & 0.928 & 0.026 \\
Logistic & -416.166 & 0.942 & 0.024 \\
Schnute & -480.879 & 0.945 & 0.023 \\
Weibull & -421.865 & 0.943 & 0.024 \\
Richards & -437.315 & 0.848 & 0.023 \\
Chapman-Richards & -239.112 & 0.934 & 0.025 \\
von Bertalanffy & -436.777 & 0.943 & 0.023 \\
Morgan-Mercer-Flodin & -350.451 & 0.939 & 0.024 \\
\hline \hline
\end{tabular}

Table 5. AICc, adjusted $R^{2}$ and RMSE values for 


$$
f(x)=(a+b \exp (c x))^{d}
$$

where, $f$ is the muscle ratio, $x$ is the trim (mm), $a=-7.55 q+7.81, b=-79.39 q+74.08, c=-0.02 q-0.25, d=$ $0.34 q-0.33$, and $q$ is the lean muscle ratio. The trimmed fat ratio is calculated as 1 - trimmed muscle ratio. Thus, if the trim ( $\mathrm{mm}$ ) and weight of the trimmed primal is known, then the weight of the trimmed fat can be calculated.

\section{ACKNOWLEDGEMENTS}

Funding to conduct this work from Meat and Livestock Australia and the CRC for Beef Genetic Technologies is gratefully acknowledged.

\section{REFERENCES}

Akaike, H. (1974). A new look at the statistical model identification. IEEE Transactions on Automatic Control, 19(6): 716-772.

Fekedulegn, D., M.P. Mac Siurtain, and J.J. Colbert (1999). Parameter estimation on nonlinear growth models in forestry. Silva Fennica, 33(4): 327-336.

Frigerio, N.A., R.F. Coley and M.J. Sampson (1972). Depth dose determinations I. Tissue-equivalent liquids for Standard Man and muscle. Physics in Medicine and Biology, 17(6): 792.

Greenwood P.L., J.P. Siddell, M. J. McPhee, B.J. Walmsley, G. Geeskink and D.W. Pethick (2011). Development of fat depots and associations with beef quality. Proceedings of the 8th International Symposium on the Nutrition of Herbivores (ISNH8). Adv Anim Biosci 2:498.

Hurvich, C.M.and C.L. Tsai (1989). Regression and time series model selection in small samples. Biometrica, 76: 297-307.

Khamis, A., Z. Ismail, K. Haron and A.T. Muhammad (2005). Nonlinear Growth Models for Modelling Oil Palm Yield Growth. Journal of Mathematics and Statistics, 1(3): 225-233.

Navajas, E.A., C.A. Glasbey, A.V. Fisher, D.W. Ross, J.J. Hyslop, R.I. Richardson, G. Simm, and R. Roehe (2010). Assessing beef carcass tissue weights using computed tomography spirals of primal cuts. Meat Science, 84: 30-38.

Nord, R.H. and R.K. Payne (1995) Body composition by dual-energy Xray absorptiometry - a review of the technology. Asia Pacific Journal of Clinical Nutrition, 4(1): 173-175.

Schnute, J. (1981). A versatile growth model with statistically stable parameters. Canadian Journal of Fisheries and Aquatic Sciences, 38: 1128-1140.

Walmsley, B.J., V.H. Oddy, M.J. McPhee, D.G. Mayer and W.A. McKiernan (2011). Development of the BeefSpecs fat calculator: A tool designed to assist decision making to increase on-farm and feedlot profitability. In 'MODSIM 2011 International Congress on Modelling and Simulation.' (F. Chan, D. Marinova and RS. Anderssen eds.). Modelling and Simulation Society of Australia and New Zealand. Perth Convention and Exhibition Centre, Perth, Australia. p 898-904. 